\title{
Inducible Expression of a Phytolacca heterotepala Ribosome- Inactivating Protein Leads to Enhanced Resistance Against Major Fungal Pathogens in Tobacco
}

\author{
Giandomenico Corrado, Pasquale Delli Bovi, Rosalia Ciliento, Luciano Gaudio, \\ Antimo Di Maro, Serena Aceto, Matteo Lorito, and Rosa Rao
}

First and eighth authors: Dipartimento di Scienze del Suolo, della Pianta e dell'Ambiente, Università di Napoli "Federico II"; second, fourth, and sixth authors: Dipartimento di Genetica, Biologia Generale e Molecolare, Università di Napoli "Federico II"; third and seventh authors: Dipartimento di Arboricoltura, Botanica e Patologia Vegetale, Università di Napoli "Federico II"; and fifth author: Dipartimento di Scienze della Vita, Seconda Università degli Studi di Napoli.

Accepted for publication 15 October 2004.

\begin{abstract}
Corrado, G., Delli Bovi, P., Ciliento, R., Gaudio, L., Di Maro, A., Aceto, S., Lorito, M., and Rao, R. 2005. Inducible expression of a Phytolacca heterotepala ribosome-inactivating protein leads to enhanced resistance against major fungal pathogens in tobacco. Phytopathology 95:206215 .

Plant genetic engineering has long been considered a valuable tool to fight fungal pathogens because it would limit the economically costly and environmentally undesirable chemical methods of disease control. Ribosome-inactivating proteins (RIPs) are potentially useful for plant defense considering their antiviral and antimicrobial activities but their use is limited by their cytotoxic activity. A new gene coding for an RIP isolated from leaves of Phytolacca heterotepala was expressed in tobacco under the control of the wound-inducible promoter of the bean polygalac-
\end{abstract}

ABSTRACT

One of the main challenges of plant biotechnology is the incorporation of effective resistance traits against more than a single fungal pathogen and several approaches have been tested (1). Genes to be genetically engineered into plants usually have been selected considering their role in a disease resistance pathway or the toxicity of their products to fungal growth in vitro (13). Typically, the increased resistance is achieved through transgenic high-level synthesis of a single or a combination of antifungal proteins (1).

Among the plant proteins potentially useful to genetically engineer broad-spectrum pathogen resistance, ribosome-inactivating proteins (RIPs) have been considered of great interest for their supposed role as endogenous defense proteins and their catalytic activity (15). Primarily, RIPs inhibit protein biosynthesis in eukaryotes by virtue of their $\mathrm{N}$-glycosidic cleavage activity of the rRNA large subunit (18) but they can also stimulate endogenous defense mechanisms when expressed in plants (28). However, while there is conclusive evidence of broad-spectrum antiviral activity of RIP expression in planta, enhanced fungal resistance has been obtained using cereal or mutated Phytolacca RIPs lacking ribonucleasic activity, which do not have cytotoxic effects in

Corresponding author: R. Rao; E-mail address: rao@unina.it

The nucleotide sequence of the PhRIP I cDNA will appear in the NCBI, EMBL, and GenBank Nucleotide Sequence Database as accession no. AY327475.

DOI: 10.1094/PHYTO-95-0206

(c) 2005 The American Phytopathological Society turonase-inhibiting protein I gene to increase resistance against different fungal pathogens, because an individual RIP isolated from $P$. heterotepala showed direct antifungal toxicity. Phenotypically normal transgenic lines infected with Alternaria alternata and Botrytis cinerea showed a significant reduction of leaf damage while reverse transcription-polymerase chain reaction and western analysis indicated the expression of the RIP transgene upon wounding and pathogen attack. This work demonstrates that use of a wound-inducible promoter is useful to limit the accumulation of antimicrobial phytotoxic proteins only in infected areas and that the controlled expression of the PhRIP I gene can be very effective to control fungal pathogens with different phytopathogenic actions.

Additional keywords: broad-spectrum resistance, plant biotechnology. plants, or plant RIPs whose constitutive expression led to phenotypic abnormalities (15). Moreover, RIP-associated broad resistance against agronomically important fungal pathogens has not yet been reported (16).

Species of the family Phytolaccaceae represent an important, though not fully investigated, source of RIPs (15). One of the first purified and characterized plant RIPs was the pokeweed antiviral protein (PAP) from Phytolacca americana, whose transgenic expression in tobacco and potato led to resistance against viral infections (12). Nonetheless, some restrictions on the possible widespread use of this RIP as an antimicrobial protein were also reported, as PAP expression was found to be phytotoxic and produced a stunted and mottled plant phenotype (12). Regrettably, such phenomenon has been also described for many RIPs expressed in mono- and dicots $(2,6,10)$. Consequently, efforts have been made to exploit alternative strategies. One approach has been the preparation of a series of mutated PAP variants. The transgenic expression in tobacco of the mutant protein PAP-C, lacking 25 amino acids at the $\mathrm{C}$ terminus and then unable to depurinate rRNA, conferred resistance against Potato virus $X(25)$ and the fungal pathogen Rhizoctonia solani (28). Although considerable progresses in understanding the biological role of RIPs have been obtained with this strategy, some drawbacks remain unsolved. It is predicted that the C-terminal deletion reduces the stability of the PAP protein (25), and therefore the accumulation of the PAP-C and other RIP variants may not occur at an adequate level in different plant species (2). Moreover, the presence of both $\mathrm{N}$ - and C-terminal domains of at least some RIPs was necessary for reaching a high level of expression (9). Finally, it should not 
be overlooked that $N$-glycosidic activity is useful to maintain the broad-spectrum antimicrobial and antiviral effects of RIPs $(15,16)$.

An alternative approach to the selection and the transgenic expression of mutated inactive forms of phytotoxic antimicrobial proteins is to exploit inducible promoters to confine the expression of the transgene at specific sites. In this case, a successful improvement of the resistance against fungal pathogens will depend on the ability to restrict the accumulation of a toxic protein to infected and wounded sites, with the probable advantage of exploiting the phytotoxic activity to generate a rapid cell death that would inhibit fungal growth (24).

In this paper, we report the successful transgenic expression in phenotypically normal tobacco plants of a new antifungal RIP from $P$. heterotepala ( $\mathrm{H}$. Walt.) under the control of a woundinducible promoter and its effect against two different major fungal pathogens.

\section{MATERIALS AND METHODS}

DNA manipulation. A full-length clone coding for the PhRIP I protein was identified by screening a cDNA expression library with anti-Phytolacca RIP antibody (22). The library was constructed from $3 \mu \mathrm{g}$ of poly $(\mathrm{A})^{+} \mathrm{RNA}$ of mature leaves in Uni-Zap XR vector (Stratagene, La Jolla, CA) according to the instruction of the ZAP-cDNA synthesis kit (Stratagene). Leaves were harvested from plants at the "Orto Botanico" of the University of Naples "Federico II". Standard molecular techniques were used for cloning experiments (22). The PhRIP I cDNA coding sequence was cloned as polymerase chain reaction (PCR) product by addition of the restriction sites BamHI and KpnI to the termini of Pfu (Stratagene) amplified DNA and replaced the gus coding sequence in the binary vector pBIN121 (Clontech, Milano, Italy), yielding the p35SRIP plasmid. The polygalacturonase-inhibiting protein I (PGIP I) gene wound-inducible promoter from Phaseolus vulgaris was isolated form the plasmid p2004Gus (3) as HindIII/ BamHI fragment and replaced the Cauliflower mosaic virus (CaMV) 35S promoter of the p35SRIP, yielding the pGIPRIP vector.

For Southern hybridization, genomic DNA from plants was isolated using a CTAB-based method (26) and digested with fivefold excess of restriction enzyme according to the manufacturer recommendations (Promega, Milano, Italy). DNA molecules, separated by agarose gel electrophoresis, were transferred onto Hybond-N nylon membranes (Amersham, Uppsala, Sweden) as previously reported (22). Hybridization of immobilized DNA and probe synthesis were carried out essentially as described previously (22).

Plant transformation. For transformation experiments, Nicotiana tabacum 'Samsun' NN tobacco plants were grown under sterile conditions from seeds. Agrobacterium tumefaciens-mediated leaf disk tobacco transformation and regeneration of antibiotic-resistant plants were performed according to procedures described previously (29). Homozygous progeny plants $\left(\mathrm{T}_{2}\right)$ were identified by successive rounds of selection in kanamycincontaining ( $50 \mu \mathrm{g} / \mathrm{liter})$ medium and molecular analysis (PCR and Southern).

Purification of PhRIP I and in vitro antifungal test. The PhRIP I protein was purified from $P$. heterotepala leaves and sequenced as described previously (4). Briefly, $100 \mathrm{~g}$ of leaves was homogenized in phosphate buffer containing $0.14 \mathrm{M} \mathrm{NaCl}$, and after subsequent precipitations with $\left(\mathrm{NH}_{4}\right)_{2} \mathrm{SO}_{4}$, the fraction containing $\mathrm{N}$-glycosidic activity was subjected to sequential chromatographies: (i) on an S-Sepharose Fast Flow column $(20 \mathrm{~cm}$ long, $3 \mathrm{~cm}$ in diameter) in $10 \mathrm{mM} \mathrm{Na}$-acetate buffer $(\mathrm{pH} \mathrm{4.5)}$, first washed with the same buffer until the absorbance at $280 \mathrm{~nm}$ was below 0.05 , and then with $5 \mathrm{mM}$ Na-phosphate buffer $(\mathrm{pH} 7.2)$ followed by elution with $1 \mathrm{M} \mathrm{NaCl}$ in $5 \mathrm{mM} \mathrm{Na}$-phosphate buffer
(pH 7.2); (ii) on a Sephacryl S-100 column, equilibrated and eluted with $0.35 \mathrm{M} \mathrm{NaCl}$ in $20 \mathrm{mM}$ Na-phosphate buffer (pH $7.2)$; and (iii) on a CM-52 column (25 cm 1ong, $1.2 \mathrm{~cm}$ in diameter) equilibrated in $5 \mathrm{mM} \mathrm{Na}$-phosphate buffer and eluted with an $\mathrm{NaCl}$ gradient up to $0.1 \mathrm{M}$. Fractions with $\mathrm{N}$-glycosidic activity were individually rechromatographed on an S-Sepharose Fast Flow column $(20 \mathrm{~cm}$ long, $3 \mathrm{~cm}$ in diameter) and eluted with a $0 \pm 0.1 \mathrm{M} \mathrm{NaCl}$ linear gradient in $5 \mathrm{mM} \mathrm{Na}$-phosphate buffer (total volume $500 \mathrm{ml}$ ). All columns and apparatus were purchased from Amersham. From the last purification step, 6 of 10 major protein peaks showed both $N$-glycosidic activity by the aniline assay (14) and cross reacted with anti-P. dioica RIP antibodies using an enzyme-linked immunosorbent assay (ELISA) (4). Purity of protein preparations was checked by reverse-phase chromatography on a Vidac C4 column and found to give a single peak. Protein samples eluted from this column were used to determine the molecular weight by electro-spray mass spectrometry. Purity and relative molecular masses were also determined by sodium dodecyl sulfate-polyacrylamide gel electrophoresis (SDSPAGE). The antifungal properties of the purified protein were tested in vitro against Botrytis cinerea as described (13). Briefly, flat-bottomed ELISA plates containing assay mixtures with the RIP at different concentrations and fungal spores were observed at different times by using an inverted microscope for evaluation of spore germination. The significance of the data was assessed by Duncan grouping analysis.

Expression analysis by reverse transcription-PCR. Total RNA was extracted from leaves using a small-scale preparation method (26). Leaf samples were harvested from infected plants, 5 days following inoculation, when the presence of fungal pathogens was clearly visible. For wounding experiments, two leaves of each plant were pierced with several sterile paper clips and damaged tissues were harvested $72 \mathrm{~h}$ after the treatment. For the control treatment, two leaf disks of approximately $1 \mathrm{~cm}$ diameter were used for RNA isolation from undamaged and uninfected plants. To perform reverse transcription (RT)-PCR amplifications, $10 \mu \mathrm{g}$ of total RNA was treated with 7.5 units of RNase-free DNase I (Amersham) at $37^{\circ} \mathrm{C}$ for $30 \mathrm{~min}$ in $0.5 \times$ First Strand Buffer (Invitrogen, Milano, Italy). The first-strand cDNA synthesis was carried out with $2 \mu \mathrm{g}$ of DNA-free RNA with the Superscript II (Invitrogen) enzyme according to the manufacturer's instructions. One tenth of the mixture was used for the amplification with 1 unit of Taq polymerase (Promega). The amplification of the cDNA coding for the elongation factor 1- $\alpha$ gene, a ubiquitously expressed gene (11), served as a control for cDNA synthesis and PCR efficiency in the different samples. The sequences annealed by the two primers (EF1, 5'-GTC AAG AGC ATC AAG AAG TG; and EF2, 5'-AGA CCA CCA AGT ACT ACT GC) are localized in the exon I and exon II of the EFI- $\alpha$ gene, respectively, for the detection of possible contaminant DNA in the PCR amplifications. As controls, $100 \mathrm{ng}$ of genomic DNA and a cDNA synthesis water-negative sample were also subjected to the amplification. The sequence of the primers for the detection of PhRIP I-specific transcript is as follows: P1, 5'-GCC AAG ATG TAG AGA CTA C; and P2, 5'-CCA CTT GGC ACC ACT GGC.

Western analysis. For the detection of the PhRIP I protein in $B$. cinerea-infected plants, leaf tissue around the lesion was harvested 5 days after inoculation. Water soluble proteins were extracted by homogenization and sonication of plant tissue in $100 \mu \mathrm{l}$ of ice-cold protein extraction buffer $(50 \mathrm{mM}$ Tris and $1 \mathrm{mM}$ EDTA, pH 7.5). After centrifugation at $20,000 \times g$ for $15 \mathrm{~min}$ at $4^{\circ} \mathrm{C}$, the supernatant was transferred to a fresh tube and the proteins were quantified according to the Bio-Rad protein assay. Proteins $(40 \mu \mathrm{g})$ were resolved by SDS-PAGE as described (22). After electrophoresis, proteins were transferred to polyvinylidene difluoride (PVDF) membrane (Bio-Rad, Milano, Italy) by electroblotting with an EC140 Mini Blot module (E-C Apparatus Co., New York), according to the manufacturer's instructions. Filters 
were then incubated for a minimum of $1 \mathrm{~h}$ in blocking solution (5\% fat-free powder milk and $0.5 \%$ Tween 20 in $1 \times$ phosphatebuffered saline [PBS]) and then overnight with anti-Phytolacca RIP sera (4) diluted 1:1,000. Filters were rinsed in washing solution $(0.5 \%$ Tween 20 in $1 \times$ PBS $)$ three times for $10 \mathrm{~min}$. The secondary antibody, an anti-rabbit immunoglobulin $\mathrm{G}$ (whole molecule) peroxidase conjugate (Sigma, Milano, Italy), was added at a 1:6,000 dilution in blocking solution for $1 \mathrm{~h}$. After washing, bound antibodies were identified using the ECL Detection Kit (Amersham) according to manufacturer's instructions.

Disease resistance assays. Homozygous transgenic tobacco progeny plants were tested for resistance to Alternaria alternata (isolated from infected potato growing in Southern Italy) and $B$. cinerea (from tobacco). A. alternata is an airborne foliar pathogen that attacks many Solanaceae and Cucurbitaceae species, strawberry, cotton, and some fruit trees (apple, pear, and citrus) causing brown spot or leaf spot disease. B. cinerea is also an airborne pathogen that attacks fruit, stems, leaves, and flowers in a wide range of plants, causing the grey mold disease.

$A$. alternata and $B$. cinerea were grown on potato dextrose agar (PDA) plates at $25^{\circ} \mathrm{C}$ with light until sporulation, and then spores were collected and suspended in sterile distilled water at $1 \times$ $10^{6}$ conidia per $\mathrm{ml}$. Four leaves, from various positions per plant, were chosen among 10 plants (higher than $40 \mathrm{~cm}$ ) of each transgenic and control lines. Ten microliters of the spore suspension was applied between the leaf veins at three different inoculation points, and plants were grown at $20^{\circ} \mathrm{C}$ with $16 \mathrm{~h}$ diurnal light and $90 \%$ relative humidity $(\mathrm{RH})$ in a growth chamber for A. alternata and in a humid chamber at $18^{\circ} \mathrm{C}$ with $100 \% \mathrm{RH}$ for $B$. cinerea. Observations were conducted after 1, 3, and 7 days for disease reactions, which were evaluated both as size of lesion and number of inoculation points developing a lesion. For all experiments, infected plant material was plated onto acidified PDA plates to verify the presence of the test fungus, and isolates obtained from infected plants were maintained in culture to be used for subsequent inoculations. Each experiment contained three or more replications for each line and was repeated three times.

\section{RESULTS}

Tobacco transformation with the cDNA encoding the PhRIP I protein. A clone encoding an RIP, named PhRIP I, was isolated from a leaf cDNA library of $P$. heterotepala (Mexican pokeweed). The primary sequence of the protein encoded by the PhRIP I cDNA was compared with those of other RIPs, and the PhRIP I showed a high level of sequence similarity with other RIPs from Phytolacca species (Fig. 1). The identities of these proteins to PhRIP I reached $94 \%$ in the case of the putative product of an antiviral protein PAP cDNA sequence from $P$. acinosa (accession no. AY049785.1). Furthermore, the PhRIP I protein sequence shares with them highly conserved residues as well as the relatively well-conserved region that, as also demonstrated by mutational evidence (19), is considered to be the active site of RIP catalytic function (23). Additionally, PhRIP I has identical residues to those of the $P$. americana PAP that are directly involved in the catalytic deadenylation of rRNA (Tyr-72, Tyr-123, Glu-176, and Arg-179) and in the stabilization of ribosome binding (Trp208) (20). This sequence analysis indicates that PhRIP I shares several amino acid residues involved in cytotoxicity with other RIPs, suggesting that the activities of PhRIP I may be very similar to that of other Phytolacca RIPs.

To test if the expression of PhRIP I is able to confer protection against economically important fungal pathogens, the full-length PhRIP I cDNA coding sequence under the control of the woundinducible PGIP promoter of the bean polygalacturonase inhibitor I gene (3) was introduced in the tobacco genome. This was done to avoid constitutive expression of the RIP, thus facilitating the regeneration of phenotypically normal plants, and to ensure that transgene expression is localized to infected cells, because a large number of pathogens attack plants through previously existing wound sites. Moreover, almost all pathogenic fungi actively penetrate plant tissues, triggering the wound signal transduction pathway (1). Figure 2 shows a map of the T-DNA region of the pGIPRIP, the vector used for Agrobacterium-mediated plant transformation. In parallel, tobacco plants were also transformed with the p35SRIP, a similar pBI121 derivative in which the PhRIP $I$ gene is under the control of the CaMV $35 \mathrm{~S}$ promoter sequence. However, in comparison to the transformation with the pGIPRIP construct, attempts using the p35SRIP vector resulted in a much lower transformation efficiency, and we could not identify an expressing plant. These data suggest that PhRIP I is detrimental for tobacco transformation and regeneration when constitutively expressed in tobacco.

After co-cultivation of leaf explants with Agrobacterium and kanamycin selection of the regenerants, the transformation with the pGIPRIP vector produced various antibiotic-resistant putative transformants, named PGIPRIP. Seven lines were further analyzed, and Southern blot hybridization indicated that the number of transgenic loci ranged form one to three (Fig. 2). The seven PGIPRIP transgenics did not show, both in vitro and in greenhouse conditions, any obvious phenotypic abnormality when compared with untransformed control plants (data not shown). Rarely did we observe that some seedlings, as in the case of the PGIPRIP 2 and PGIPRIP 37 lines, had wrinkled and pale green leaves and a reduced growth rate. The proportion of seedlings displaying such behavior was very low (below 2\%), and such phenomenon was not clearly reproducible and never observed when seedlings were sown in soil.

Antifungal activity of PhRIP I on B. cinerea spores. To evaluate a direct effect of PhRIP I on fungal growth, we treated spores of $B$. cinerea with active PhRIP I purified from $P$. heterotepala. This allowed us to avoid possible contamination of synergistically or antagonistically acting molecules that may be present in protein extracts from wound-induced transgenic tobacco plants. Proteins were isolated from crude leaf extract, and Figure 3 shows the overlay gradient elution profile of the last purification step and the in vitro $N$-glycosidic activity of the two major protein peaks 4 and 5 . Further details about the isolation and the characterization of $P$. heterotepala genes and proteins with $\mathrm{N}$-glycosidic activity will be presented elsewhere. Considering that the PhRIP I cDNA was the only full-length clone to encode a product of the same molecular weight of peak 4 (PhRIP I) and that the sequence of the first 36 amino acids of the protein purified from peak 4 is identical to the $\mathrm{N}$ terminus of the PhRIP I cDNA product (from residue 23 onward) (data not shown), such protein was used for the bioassay. To evaluate its inhibitory action on fungal growth, $B$. cinerea spores were treated with various concentrations of PhRIP I. In this in vitro assay with living spores, the antifungal effect was quantified by measuring the inhibition of the spore germination. We determined the effect of the PhRIP I at different time points during the experiments and statistically significant differences were clearly seen after $20 \mathrm{~h}$. Figure 4 shows the effect of different concentrations of the PhRIP I purified protein on fungal germination. Our results indicate that $B$. cinerea germination is reduced by approximately $20 \%$ if a dose of purified PhRIP I ranging from 25 to $50 \mu \mathrm{g} / \mathrm{ml}$ is applied. Nonetheless, we did not observe a linear dose-effect inhibitory response within the concentration range tested.

Inducible expression of the PhRIP I cDNA in tobacco. The inducible expression of the PhRIP I cDNA was analyzed in the seven PGIPRIP lines. Because it has been shown that upon limited leaf damage, wound-inducible promoters normally drive transgene expression in a locally restricted manner (21), we used an RT-PCR approach. We harvested leaf tissue around the infected area; however, the dimension of the lesions differed among the seven lines tested (described below) and each leaf sample did 


$$
\begin{aligned}
& \ldots|\ldots| \ldots|\ldots| \ldots|\ldots| \ldots|\ldots| \ldots|\ldots| \ldots|\ldots| \ldots|\ldots| \ldots \mid \\
& \begin{array}{lllll}
10 & 20 & 30 & 40 & 50
\end{array}
\end{aligned}
$$

PhRIPI MKSMLVVTISVWLILAP--TSTWAVNTIIYNVGSTTISKYATFLDDLRNEAKDPNLKCYG PAP MKSMLVVTISIWLILAP--TSTWAVNTI IYNVGSTTISKȲATFENDLRNEAKDPSLKCYG PAPAP MKSMLVVTISVWLILAP--TSTWAVNTIIYNVGSTTISKȲATF̄LDNL Sap MKIYVVATIAWILLQFSAWTTTDAVTSITLDLVNPTAGQȲSSF'VDKI $\bar{R} N N V K D P N L K Y G G$

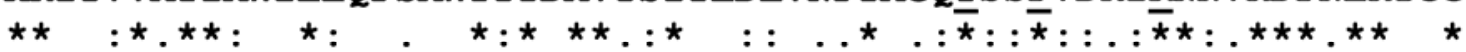

$$
\begin{aligned}
& \ldots|\ldots| \ldots|\ldots| \ldots|\ldots| \ldots|\ldots| \ldots|\ldots| \ldots|\ldots| \ldots|\ldots| \ldots|\ldots| \\
& \begin{array}{llllll}
70 & 80 & 90 & 100 & 110 & 120
\end{array}
\end{aligned}
$$

PhRIPI IPMLPNTNSNPKYVLVELQGSNKKTITLMLRRNNLYVMGYSDPFDTSKCRYHIFN-DISG PAP IPMLPNTNTNPKYVLVELQGSNKKTITLMLRRNNLYVMGYSDPFETNKCRYHIFN-DISG PaPAP IPMLPNTNPNPKYVLVELQGSNKKTITLMLRRNNLYVMGYSDPFDTNKCRYHIFS-DISG SaP TDIAVIGPPSKEKFLRINFQSSRGTVSLGLKRDNLYVVAYLAMDNTNVNRAYYFRSEITS

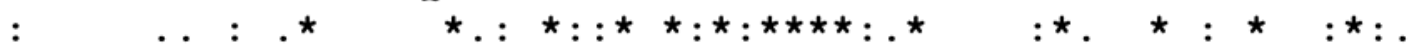

$$
\begin{aligned}
& \ldots|\ldots| \ldots|\ldots| \ldots|\ldots| \ldots|\ldots| \ldots|\ldots| \ldots|\ldots| \ldots|\ldots| \ldots \mid
\end{aligned}
$$

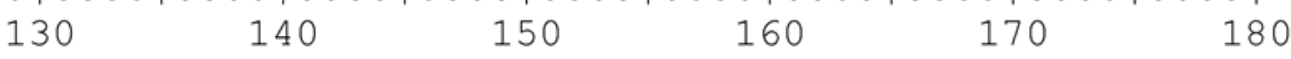

PhRIPI TERQDVETTLCPNSNSRVSKNINYDSRYPTLESKVGVK----SRSQVQLGIQILDSDIGK PAP TERQDVETTLCPNANSRVSKNINFDSRYPTLESKAGVK----SRSQVQLGIQILDSNIGK PAPAP TERQDVETTLCPNPNSRVSKNINYDSRYPTLESKAGVK----SRSQVQLGIQILDSNIGK Sap AES----TALFPEATTANQKALEYTEDYQSIEKNAQITQGDQSRKELGLGIDLLSTSMEA

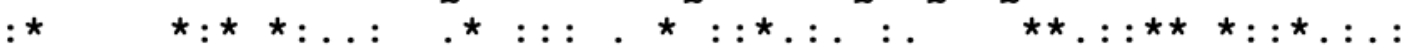

$$
\begin{aligned}
& \ldots|\ldots| \ldots|\ldots| \ldots|\ldots| \ldots|\ldots| \ldots|\ldots| \ldots|\ldots| \ldots|\ldots| \ldots|\ldots| \\
& \begin{array}{lllll}
190 & 200 & 210 & 220 & 230
\end{array}
\end{aligned}
$$

PhRIPI ISGVTSFSEKTEAEFLLVAIQMVSEAARFKYIENQVKTNFNRAFNPNPKVLNLEETẄGKI PAP ISGVMSFTEKTEAEFLLVAIQMVSEAARFKY IENQVKTNFNRAFNPNPKVLNLQETWGKI PaPAP ISGVTSFTEKTEAEFLLVAIQMVSEAARFKYIGNQVKTNFNRAFNPNPKVLNLEETWGKI Sap VN-KKARVVKDEARFLLIAIQMTAEAARFRYIQNLVIKNFPNKFNSENKVIQFEVNWKKI

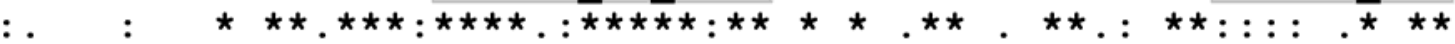

$$
\begin{aligned}
& \ldots|\ldots| \ldots|\ldots| \ldots|\ldots| \ldots|\ldots| \ldots|\ldots| \ldots|\ldots| \ldots|\ldots| \ldots|\ldots|
\end{aligned}
$$

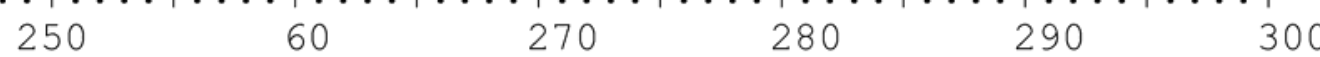

PhRIPI STAIH-DAKNGVLPKPLELVDASGAKWIVLRVDEMKPDVALLNYVSGSCQTTYNQNAMFP PAP STAIH-DAKNGVLPKPLELVDASGAKWIVLRVDEIKPDVALLNYVGGSCQTTYNQNAMFP PaPAP STAIH-DAKNGVLPKPLELVDASGAKWIVLRVDDIKPDVALLNYVGGSCQTTYNQNAMFP Sap STAIYGDAKNGVFNKDYDFGFG-----KVRQVKDLQ--MGLLMYLGKPKSSNEAN-----

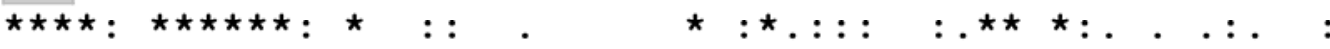

$\ldots|\ldots| \ldots|\ldots|$.

$$
310 \quad 320
$$

PhRIPI QLIMSTYYNYMANLGDLFEEF

PAP QLIMSTYYNYMVNLGDLFEGF

PaPAP QLIMSTYYNYMANLGDLFEGF

SaP ----STVRHYGPLKPTLLIT-

$$
\text { ** }: \text { * } \quad \text { * }
$$

Fig. 1. Sequence alignment of the Phytolacca heterotepala ribosome-inactivating protein I (PhRIP I) and other plant RIPs. The predicted amino acid sequence encoded by the PhRIP I cDNA was aligned with the pokeweed antiviral protein PaPAP from P. acinosa (accession no. AY049785.1), the protein in the database with the highest similarity (94\%) to PhRIP I, and two well-characterized plant RIPs, PAP (accession no. P10297) from P. americana and Saporin-6 (Sap) (accession no. P20656) from Saponaria officinalis. Amino acid identities and similarities were scored by pairwise sequence comparisons and the alignment was created using Clustal X (version 1.83) at default parameters. Asterisks (*) symbolize amino acid identity while one dot (.) or two dots (:) mark the occurrence of a weakly or a strongly conserved amino acid group, respectively. The N-terminal residues believed to be absolutely conserved among all plant RIPs are underlined. Shaded areas indicate the homologous region around the proposed active site while the amino acids involved in $N$-glycosidic activity are in black boxes. 


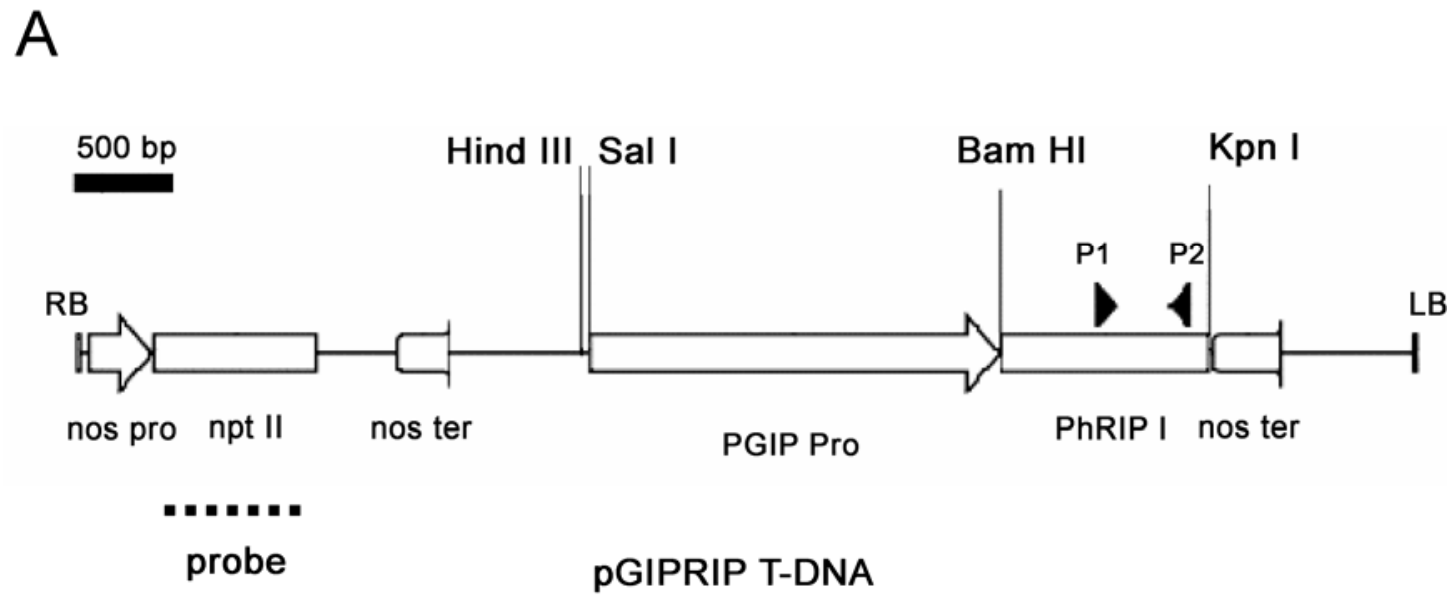

B

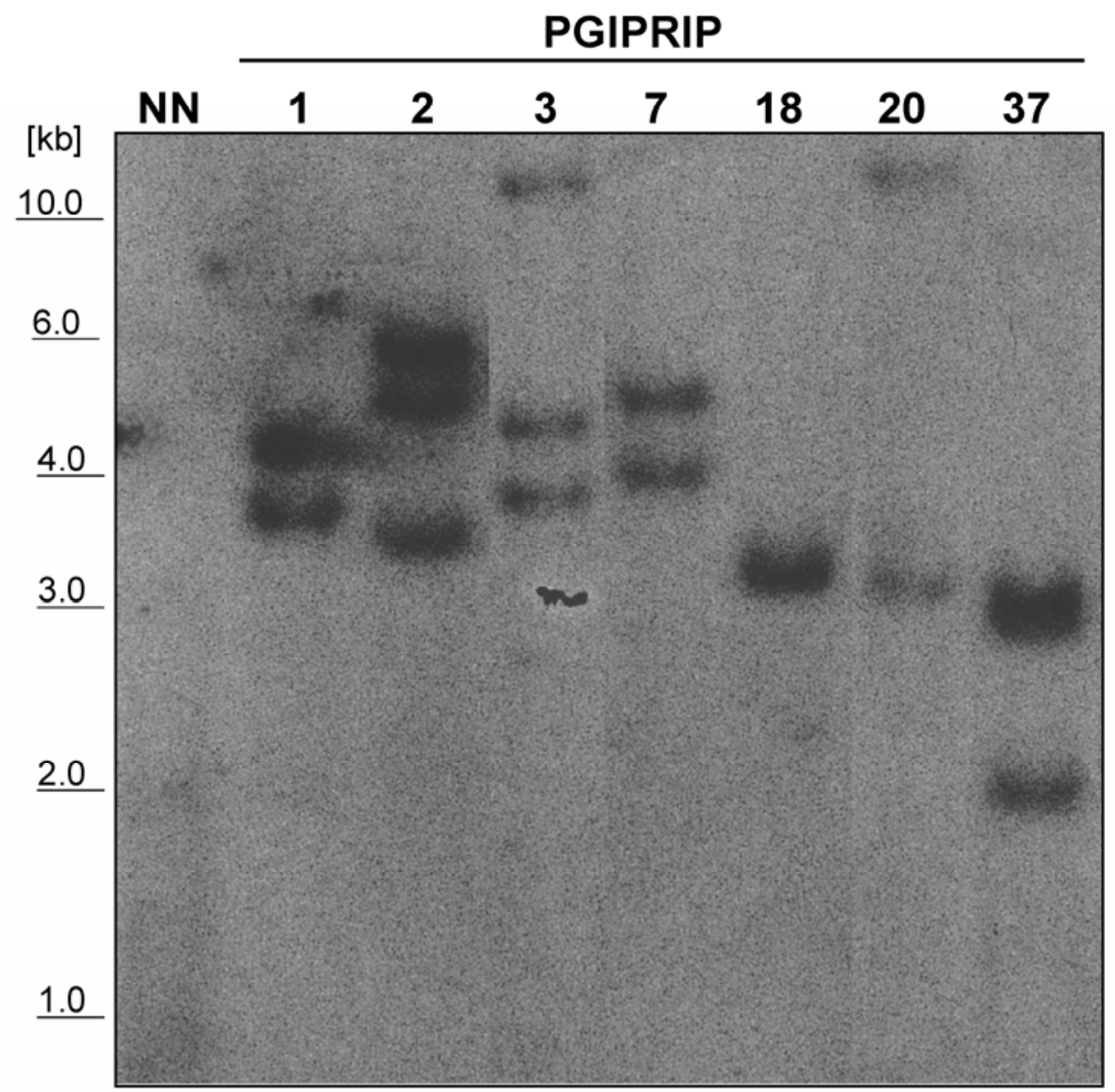

Fig. 2. T-DNA map pGIPRIP vector and DNA gel blot analysis of the transgenic PGIPRIP lines. A, Schematic representation of the T-DNA region of the pGIPRIP vector employed for the Agrobacterium-mediated tobacco transformation, showing unique restriction sites. Scale size is presented on the top-left corner. Arrows represent cis-controlling elements and black triangles indicate the location of the primers P1 and P2 used for reverse transcription-polymerase chain reaction analysis. A dashed line underlines the region hybridized in the Southern analysis. RB, T-DNA right border sequence; nos pro, nopaline synthase gene promoter; npt II, neomycin phosphotransferase gene; nos ter, poly(A) addition sequence of the nos gene; PGIP Pro, bean polygalacturonase gene I promoter; PhRIP I, Phytolacca heretotepala RIP I cDNA sequence; and LB, T-DNA left border sequence. B, Genomic DNA (10 $\mu$ g) from a Nicotiana tabacum 'Samsun' NN plant (NN) and transgenic PGIPRIP primary transformants was digested with HindIII, which cuts once in the T-DNA of the binary vector (A). After gel electrophoresis, the DNA was transferred onto a nylon membrane and hybridized with an $n p t I I$ probe. Numbers at the left margin indicate marker fragment sizes in kilobase pairs. 
not contain the same amount of tissue. This inevitably may result in the averaging of the transgene expression in different leaf areas because of the bulk of the surrounding uninfected cells. As a control, the expression of the PhRIP I gene was also analyzed in wounded plants.

In all these experiments, PCR amplifications were carried out on reverse-transcribed mRNA using the primers EF1 and EF2 for the constitutively expressed elongation factor $1-\alpha$ gene, and the primers P1 and P2 for the detection of the PhRIP I transcripts. Because the sequences annealed by the EF1 and EF2 primers are localized in exon I and II of the EFI- $\alpha$ gene, by using these primers it is also possible to detect contaminant genomic DNA. The location of the P1 and P2 primers along the PhRIP I is indicated in Figure 2.

Figure 5 shows that the PhRIP I gene transcripts were detectable in the pathogen-resistant PGIPRIP lines only upon wounding and pathogen infection. Moreover, considering that in some cases the heterologous RIP expression in plants may be impaired by the stability of the protein $(2,25)$, we also determined the presence of the PhRIP I protein after the pathogen attack in leaf tissues around the necrotic lesions. Western analysis showed a single band of approximately $30 \mathrm{kDa}$ in the transgenic lines (Fig. 6), implying that the PhRIP I gene is correctly translated and the transgenic protein is sufficiently stable to be detected by standard immunological procedures.

Phytopathological evaluation of PGIPRIP lines. In vivo bioassays with the foliar pathogens $A$. alternaria and $B$. cinerea were conducted in highly favorable conditions for fungal attack in terms of $\mathrm{RH}$ and temperature, using inocula with concentration of $1 \times 10^{6}$ spores per $\mathrm{ml}$, and both the dimension of lesions and the ability of the pathogen to spread on leaf surface were monitored at different time-points. In spite of the favorable conditions, the seven transgenic PGIPRIP lines showed increased resistance to both $A$. alternaria and $B$. cinerea as indicated by the reduction of the area of the lesion and the number of inoculation points developing lesions (Fig. 7). It is worthy to note that in cases such as that of lines PGIPRIP 1 and 37, a high level of resistance was observed.

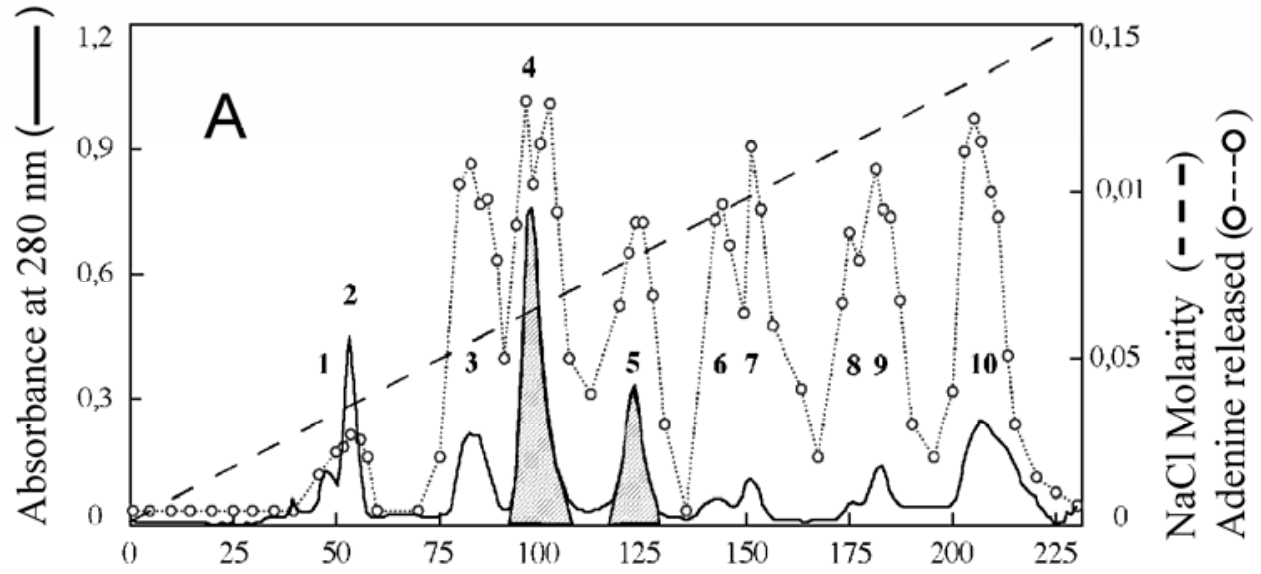

Fraction number $(4 \mathrm{ml})$

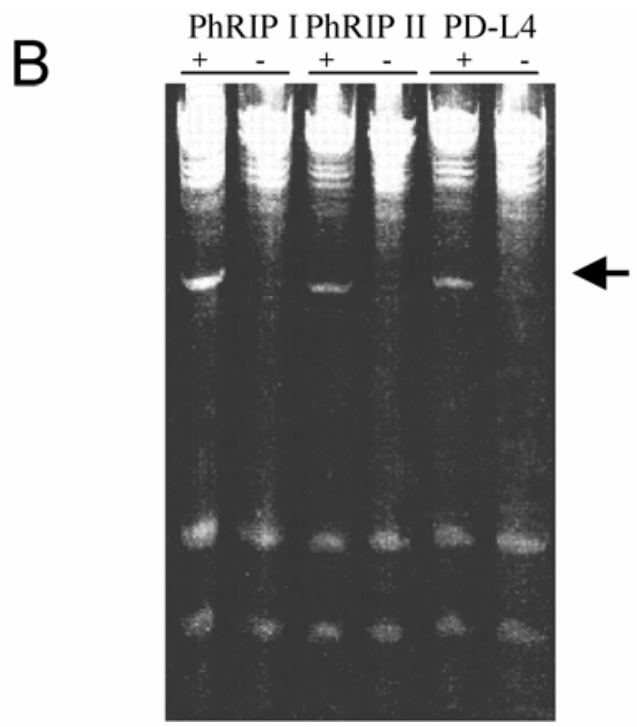

Fig. 3. Purification of enzymatically active Phytolacca heterotepala ribosome-inactivating protein I (PhRIP I) from P. heterotepala leaves. A, Ion-exchange chromatography elution profile of the final purification step of crude extract from P. heterotepala leaves. B, Depurination activity of PhRIP I (peak 4) and PhRIP II (peak 5) on rRNA. The P. dioica-L4 RIP (PD-L4) was used as positive control. The arrow points to the diagnostic Endo's fragment released from rRNA, while + and - indicate the presence or absence, respectively, of aniline treatment. 


\section{DISCUSSION}

The objective of this work was to characterize the antifungal activity, both in vitro and in planta, of a new type-I RIP isolated from $P$. heterotepala. Considering the recurring adverse effects of Phytolacca RIPs transgenic expression, we tested the strategy of using a wound-inducible promoter to control the PhRIP I transgene in tobacco to increase resistance against fungal pathogens with different phytopathogenic mechanisms, trying to exploit the localized cytotoxic action of a Phytolacca RIP to generate rapid cell death in infected plant cells.

Not surprisingly, despite repeated attempts, we were not able to regenerate a transgenic plant expressing the PhRIP I gene under the control of the CaMV $35 \mathrm{~S}$ constitutive promoter. In contrast, a similar vector with the PGIP promoter instead of the CaMV 35S successfully produced expressing transgenic lines, suggesting that the lack of transformants reflects a detrimental effect of PhRIP I

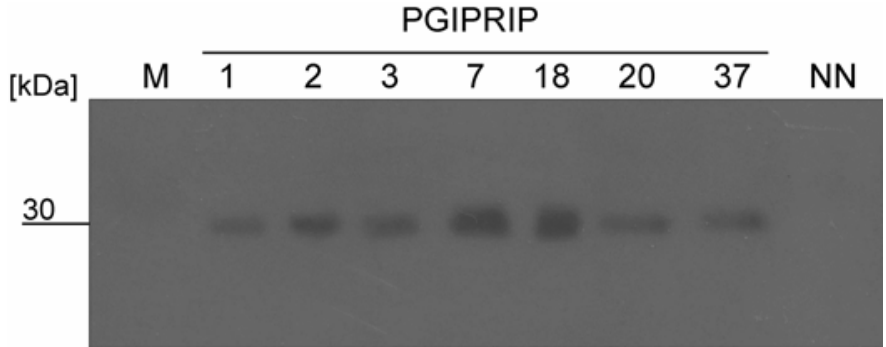

Fig. 6. Protein gel blot analysis of Botrytis cinerea-infected PGIPRIP lines using an anti-Phytolacca RIP polyclonal antibody. Protein extracts were prepared from leaf sectors of transgenic PGIPRIP lines and from untransformed Nicotiana tabacum 'Samsun' NN plant (NN) 5 days following B. cinerea infection. Proteins $(40 \mu \mathrm{g})$ were run in a $10 \%$ sodium dodecyl sulfate-polyacrylamide gel. M, molecular mass marker.

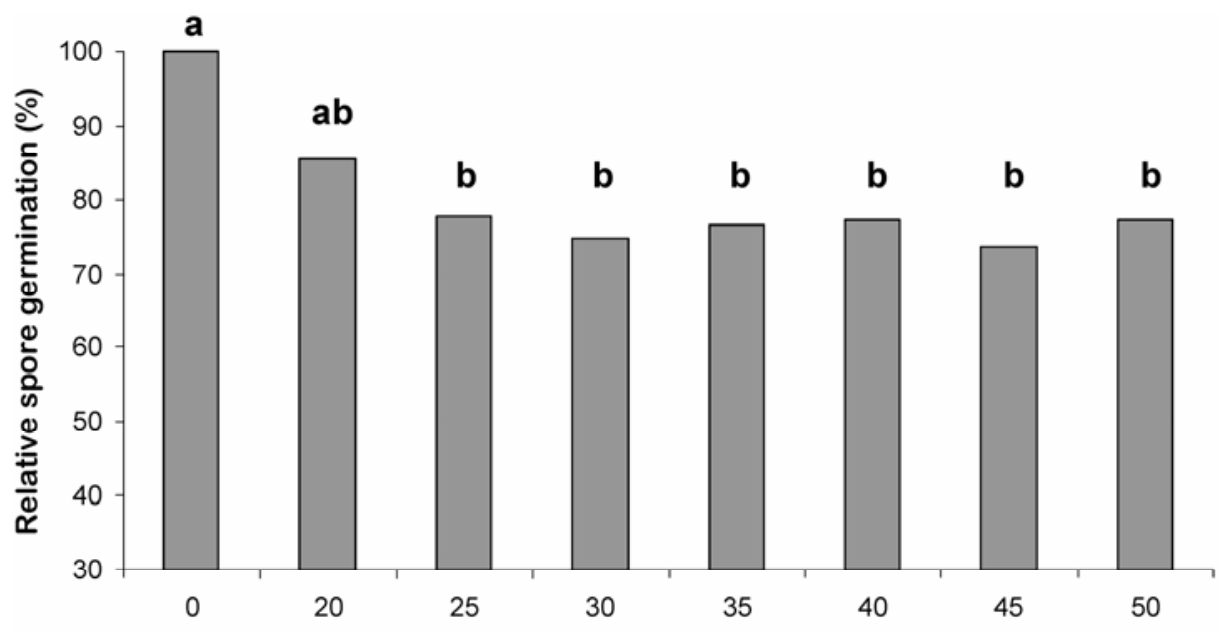

PhRIP I concentration $(\mu \mathrm{g} / \mathrm{ml})$

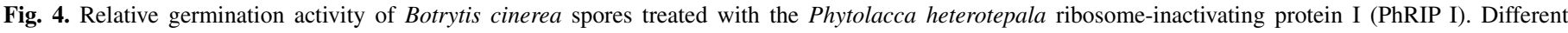

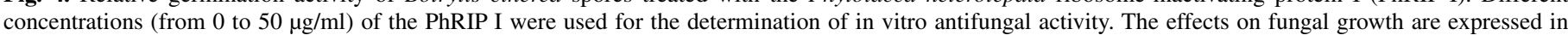

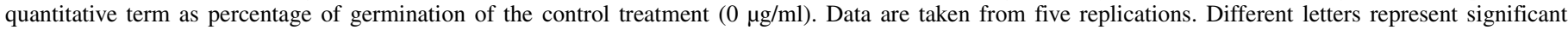
differences (Duncan; $P<0.05$ ) between treatments.

\section{Elongation Factor $1-\alpha$}

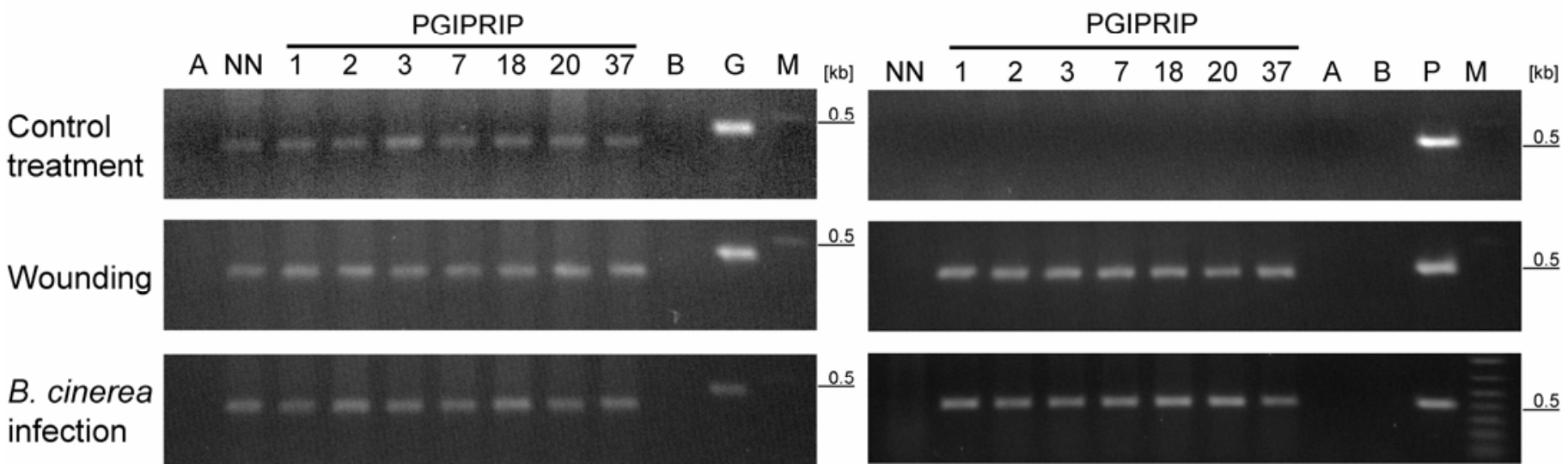

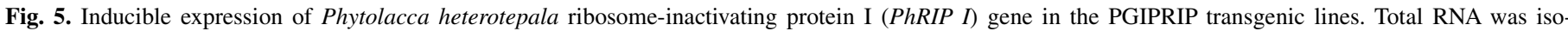

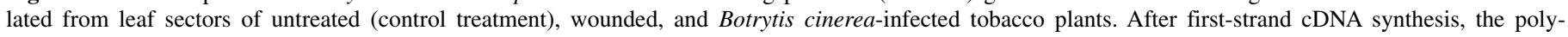

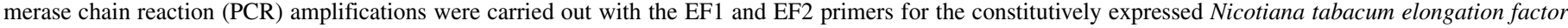

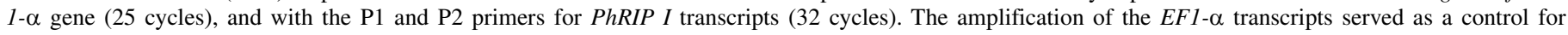

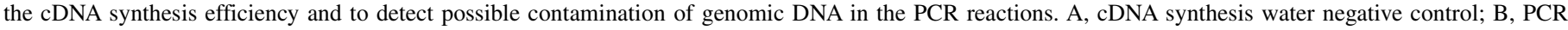

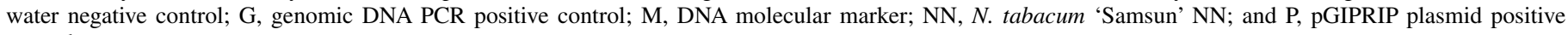
control. 
expression during the plant regeneration process or growth. Controlled gene expression systems are suitable to drive in plants genes with a dominant negative effect on plant regeneration or growth (5) and our preference went to the full-length woundinducible promoter of the bean polygalacturonase inhibitor gene I. In this paper, we report that such a wound-inducible promoter can successfully drive the expression of a toxic protein in tobacco upon wounding and pathogen-derived leaf damage, without a detectable background expression able to produce the phenotypic abnormalities frequently associated with constitutive ectopic RIP expression $(2,12)$.

Our data demonstrate that the purified active PhRIP I protein has a direct antifungal activity, an agronomically useful feature not always present in plant RIPs (17). We found that the PhRIP I significantly inhibits the germination of $B$. cinerea spores, but we did not observe a dose-dependent response. It has been reported that the in vitro inhibition of fungal growth mainly depends on complex interactions between RIPs and fungal cells (17); hence,

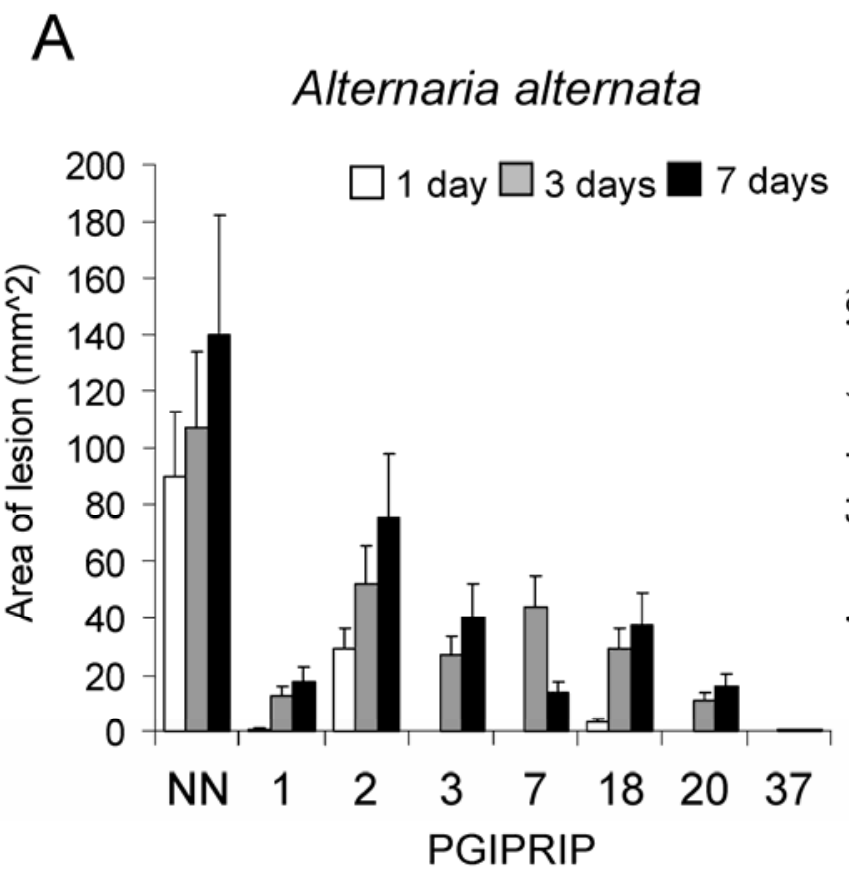

B

Alternaria alternata

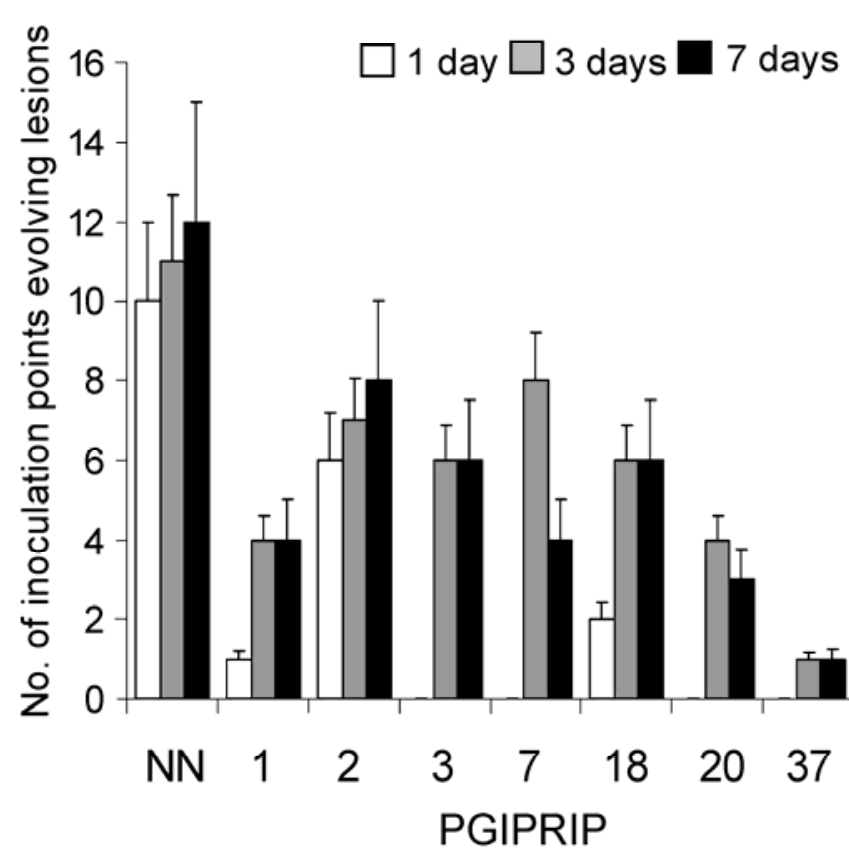

Botrytis cinerea

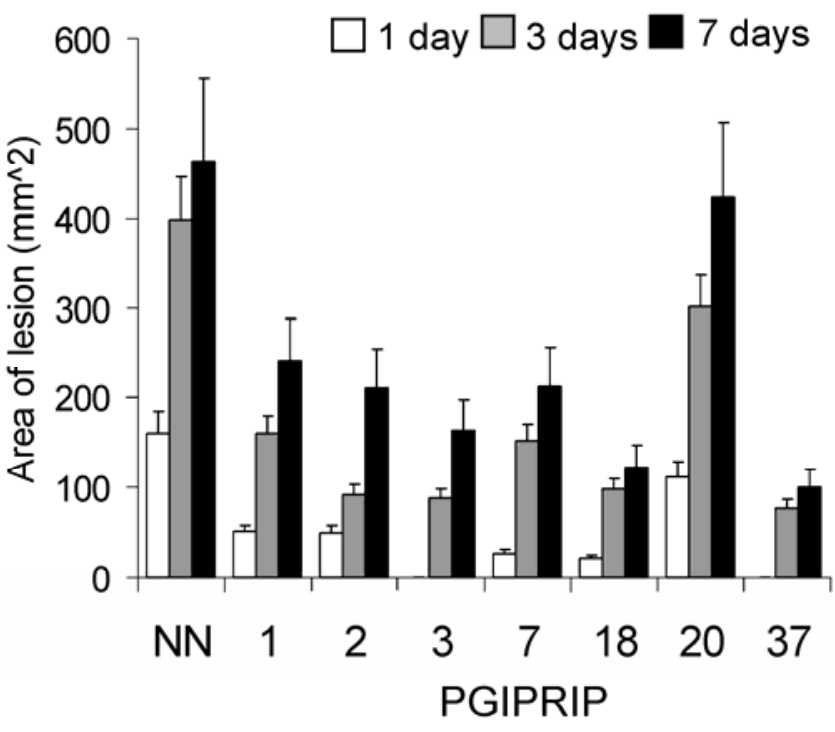

Botrytis cinerea

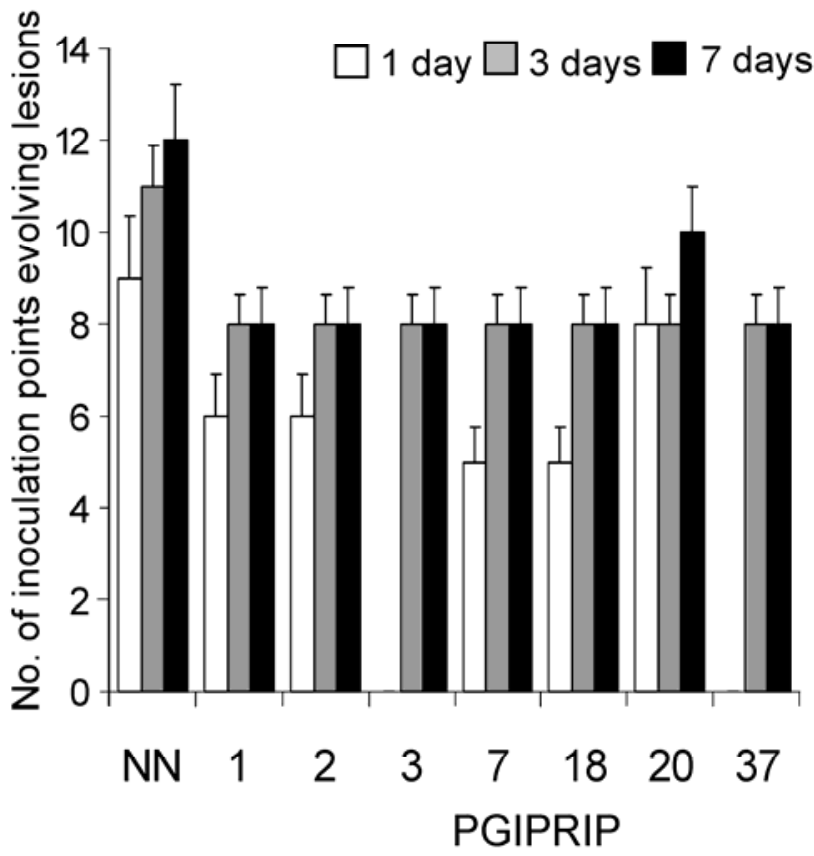

Fig. 7. Enhanced resistance to Alternaria alternata and Botrytis cinerea of the PGIPRIP lines. Resistance response to A. alternata and B. cinerea artificial infection by transgenic PGIPRIP tobacco lines and untransformed controls $(\mathrm{NN})\left(\right.$ spore concentrations used for pathogen infection: $\left.1 \times 10^{6}\right)$. A, Mean and standard deviation of the size of lesions; and $\mathbf{B}$, number of leaf inoculation points evolving in lesion. Data were collected 1 day (white bars), 3 days (gray bars), and 7 days (black bars) following inoculation. 
it is possible that the lack of other factors, which for instance would ease the transport of some of these proteins into the fungal cytoplasm $(7,8)$, has limited a dose-dependent effect in our assay.

In the transgenic lines, in which we detected the expression of the PhRIP I transgene and the accumulation of the protein in the damaged tissues surrounding the infected areas, we observed a significant decrease of the infected leaf regions. As also demonstrated by the in vitro fungal inhibition assay, the enhanced resistance of the expressing PGIPRIP lines implies a relevant value of the PhRIP I as an antimicrobial defense protein. Moreover, both the $N$-glycosidic activity of the PhRIP I protein towards rRNA and the lack of regenerants constitutively accumulating the transgenic protein imply the possible generation of a fungal-inhibitory cytotoxic effect at the infected plant cells as consequence of the inducible gene expression (24). Additionally, considering that sequence analysis suggests similar enzymatic properties between PhRIP I and other Phytolacca RIPs, we cannot exclude that PhRIP I activates endogenous defense mechanisms (27). However, the PhRIP I gene in the PGIPRIP transgenic lines is under the control of a wound-inducible promoter and thus it would be difficult to distinguish between transgene-induced and normal plant responses, considering the lack of transgene-specific systemically mobile signals for wound-inducible promoters (5). Finally, in our specific case, it should be also considered that the presence of the antifungal PhRIP I protein, which in the PGIPRIP lines depends upon the activity of the wound-inducible PGIP promoter, is ultimately correlated to the damage produced by foliar pathogens, making quantitative correlations difficult.

In our in vivo phytopathogenic assays we observed a strong reduction of the colonization rate by the two pathogens tested, with the transgenic lines more resistant to A. alternata than $B$. cinerea. We showed that transgene expression starts only after a direct damage has been caused to the infected tissue and it conceivably allows fast-growing fungi as $B$. cinerea to move from dying infected to not yet toxic uninfected areas, implying that such defense mechanisms would probably be less effective on pertophitic fungal pathogens, whose plant colonization is headed by necrosis of the host tissue. Hence, a limit of the approach we have used may reside in the possible delay between pathogen attack and the onset of the wound-inducible expression. However, considering the limited availability of resistanceimproving genes successfully tested in vivo against very different fungal pests (13), the remarkable disease resistance improvement we obtained using an RIP from a Phytolacca plant, achieved in the absence of phytotoxicity, represents a biotechnologically interesting result, given the economical importance of the pathogens tested and their strongly different modes of phytopathogenic action.

In conclusion, our results indicate that Phytolacca species are an unexhausted source of useful antifungal proteins and demonstrate that the controlled expression in phenotypically normal plants of the $P$. heterotepala RIP I can be used as effective strategy to counteract the action of different pathogenic fungi, and considering the broad activities of other Phytolacca RIPs, it may help to obtain resistance against pathogens as varied as viruses, nematodes, and some insects.

\section{ACKNOWLEDGMENTS}

This work was partially supported by the PON-MIUR "Nuove tecnologie al servizio delle produzioni agroalimentari ecocompatibili" project. We thank F. Cervone (Università di Roma "La Sapienza") for the p2004Gus vector, A. Parente (Seconda Università degli Studi di Napoli) for critical reading of the manuscript, and N. Riccone for excellent technical support.

\section{LITERATURE CITED}

1. Campbell, M. A., Fitzgerald, H. A., and Ronald, P. C. 2002. Engineering pathogen resistance in crop plants. Transgenic Res. 11:599-613.

2. Dai, W. D., Bonos, S., Guo, Z., Meyer, W. A., Day, P. R., and Belanger, F. C. 2003. Expression of pokeweed antiviral proteins in creeping bentgrass. Plant Cell Rep. 21:497-502.

3. Devoto, A., Leckie, F., Lupotto, E., Cervone, F., and De Lorenzo, G. 1998. The promoter of a gene encoding a polygalacturonase-inhibiting protein of Phaseolus vulgaris L. is activated by wounding but not by elicitors or pathogen infection. Planta 205:165-174.

4. Di Maro, A., Valbonesi, P., Bolognesi, A., Stirpe, F., De Luca, P., Siniscalco Gigliano, G., Gaudio, L., Delli Bovi, P., Ferranti, P., Malorni, A., and Parente, A. 1999. Isolation and characterization of four type-1 ribosome-inactivating proteins, with polynucleotide:adenosine glycosidase activity, from leaves of Phytolacca dioica L. Planta 208:125-131.

5. Gatz, C. 1997. Chemical control of gene expression. Annu. Rev. Plant Physiol. Plant Mol. Biol. 48:89-108.

6. Gorschen, E., Dunaeva, M., Hause, B., Reeh, I., Wasternack, C., and Parthier, B. 1997. Expression of the ribosome-inactivating protein JIP60 from barely in transgenic tobacco leads to an abnormal phenotype and alterations on the level of translation. Planta 202:470-478.

7. Jach, G., Gornhardt, B., Mundy, J., Logemann, J., Pinsdorf, E., Leah, R., Schell, J., and Maas, C. 1995. Enhanced quantitative resistance against fungal disease by combinatorial expression of different barley antifungal proteins in transgenic tobacco. Plant J. 8:97-109.

8. Kim, J. K., Jang, I. C., Wu, R., Zuo, W. N., Boston, R. S., Lee, Y. H., Ahn, I. P., and Nahm, B. H. 2003. Co-expression of a modified maize ribosome-inactivating protein and a rice basic chitinase gene in transgenic rice plants confers enhanced resistance to sheath blight. Transgenic Res. $12: 475-484$.

9. Krishnan, R., McDonald, K. A., Dandekar, A. M., Jackman, A. P., and Falk, B. 2002. Expression of recombinant trichosanthin, a ribosomeinactivating protein, in transgenic tobacco. J. Biotechnol. 97:69-88.

10. Lam, Y. H., Wong, Y. S., Wang, B., Wong, R. N. S., Yeung, H. W., and Shah, P. C. 1996. Use of trichosanthin to reduce infection by Turnip mosaic virus. Plant Sci. 114:111-117.

11. Liboz, T., Bardet, C., Le Van Thai, A., Axelos, M., and Lescure, B. 1990. The four members of the gene family encoding the Arabidopsis thaliana translation elongation factor EF-1 alpha are actively transcribed. Plant Mol. Biol. 14:107-110.

12. Lodge, J. K., Kaniewski, W. K., and Tumer, N. E. 1993. Broad-spectrum virus-resistance in transgenic plants expressing pokeweed antiviral protein. Proc. Natl. Acad. Sci. USA 90:7089-7093.

13. Lorito, M., Del Sorbo, G., and Scala, F. 2001. Molecular approaches for increasing plant resistance to biotic and abiotic stresses. Pages 123-145 in: Breeding for Ornamental-Classical and Molecular Approaches. A. Veinstein, ed. Kluwer Academic Publishers, Dordrecht, the Netherlands.

14. Massiah, A., and Hartley, M. 1995. Wheat ribosome-inactivating proteins: Seed and leaf forms with different specificities and cofactors requirements. Planta 197:633-640.

15. Nielsen, K., and Boston, R. S. 2001. Ribosome-inactivating proteins: A plant perspective. Annu. Rev. Plant Physiol. Plant Mol. Biol. 52:785-816.

16. Nielsen, K., Payne, G. A., and Boston, R. S. 2001. Maize ribosomeinactivating protein inhibits normal development of Aspergillus nidulans and Aspergillus flavus. Mol. Plant-Microbe Interact. 14:164-172.

17. Park, S. W., Stevens, N. M., and Vivanco, J. M. 2002. Enzymatic specificity of three ribosome-inactivating proteins against fungal ribosomes, and correlation with antifungal activity. Planta 216:227-234.

18. Park, S. W., Vepachedu, R., Owens, R. A., and Vivanco, J. M. 2004. The $\mathrm{N}$-glycosidase activity of the ribosome-inactivating protein me1 targets single-stranded regions of nucleic acids independent of sequence or structural motifs. J. Biol. Chem. 279:34165-34174.

19. Poyet, J. L., Hoeveler, A., and Jongeneel, C. V. 1998. Analysis of active site residues of the antiviral protein from summer leaves from Phytolacca americana by site-directed mutagenesis. Biochem. Biophys. Res. Commun. 253:582-587.

20. Rajamohan, F., Pugmire, M. J., Kurinov, I. V., and Uckun, F. M. 2000. Modeling and alanine scanning mutagenesis studies of recombinant pokeweed antiviral protein. J. Biol. Chem. 275:3382-3390.

21. Rushton, P. J., Reinstadler, A., Lipka, V., Lippok, B., and Somssich, I. E. 2002. Synthetic plant promoters containing defined regulatory elements provide novel insights into pathogen- and wound-induced signaling. Plant Cell 14:749-762

22. Sambrook, J., Fritsh, E. F., and Maniatis, T. 1989. Molecular Cloning: A Laboratory Manual. 2nd ed. Cold Spring Harbor Laboratory, Cold Spring Harbor, NY.

23. Stirpe, F., Barbieri, L., Battelli, M. G., Soria, M., and Lappi, D. A. 1992. Ribosome-inactivating proteins from plants-Present status and future prospects. Bio-Technology 10:405-412. 
24. Strittmatter, G., Janssens, J., Opsomer, C., and Batterman, J. 1995. Inhibition of fungal disease development in plants by engineering controlled cell-death. Bio-Technology 13:1085-1089.

25. Tumer, N. E., Hwang, D. J., and Bonness, M. 1997. C-terminal deletion mutant of pokeweed antiviral protein inhibits viral infection but does not depurinate host ribosomes. Proc. Natl. Acad. Sci. USA 94:38663871 .

26. van Blokland, R., Ross, S., Corrado, G., Scollan, C., and Meyer, P. 1998. Developmental abnormalities associated with deoxyadenosine methylation in transgenic tobacco. Plant J. 15:543-551.
27. Zoubenko, O., Hudak, K., and Tumer, N. E. 2000. A non-toxic pokeweed antiviral protein mutant inhibits pathogen infection via a novel salicylic acid-independent pathway. Plant Mol. Biol. 44:219-229.

28. Zoubenko, O., Uckun, F., Hur, Y., Chet, I., and Tumer, N. 1997. Plant resistance to fungal infection induced by nontoxic pokeweed antiviral protein mutants. Nat. Biotechnol. 15:992-996.

29. Zubko, E., Adams, C. J., Machaekova, I., Malbeck, J., Scollan, C., and Meyer, P. 2002. Activation tagging identifies a gene from Petunia hybrida responsible for the production of active cytokinins in plants. Plant J. 29:797-808. 